\title{
Synthesis of Symmetrical Carboxylic Acid Anhydrides from Acyl Chlorides in the Presence of In Metal and DMF
}

\author{
Joong-Gon Kim and Doo Ok Jang ${ }^{\circ}$

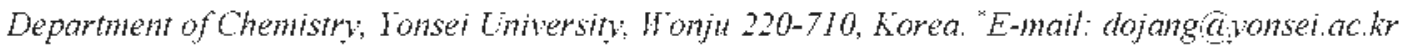 \\ $\dagger$ Biotechnologv Division, Hanwa Chemical R\&D Center. Daejeon $305-345$. Korea \\ Received Nowember 7, 2008, Accepted Nowember 20, 2008
}

Key Words: Acid anlydride, Acyl chloride, Indium, DMF

Symmetrical carboxylic acid anhydrides are valuable reagents for preparing carboxylic acid derivatives owing to their highly reactive electrophilic character. ' Carboxỵlic acid anhy'drides are typically prepared by the reaction of an acyl halide with a carboxylate metal salt, ${ }^{\text {" }}$ or with a carboxylic acid in the presence of a base. Altematively carboxylic acid anlydrides are made by the reaction of a carboxy lic acid with a powerful dehydrative coupling agent such as thionyl chloride. ${ }^{4}$ phosgene. ${ }^{5}$ carbodiimides. phosphoranes, isocyanate, "ethosyacetylene, 1, 3,5-triazines ${ }^{15}$ and trichloroacetonitrile $/ \mathrm{PPh}_{3}{ }^{11}$ Mary of these methods. however suffer from drawbacks including use of expensive and/or toxic reagents, low yields. tedious workup procedures. harsh reaction conditions and incompatibility with poly-functionalized substrates. Therefore, mild and efficient methods for prepaning carboxylic acid anlydrides are still in great demand.

Organic reactions employing indium metal have gained considerable attention because indium-mediated reactions show high reactivity and unique properties in organic or aqueous medium. ${ }^{\text {12 }}$ Indium is non-hazardous and inert towards air and water. Moreover. pretreatment is unnecessary to activate in-

Table 1. Optinizing reaction conditions.

\begin{tabular}{|c|c|c|c|c|}
\hline Entry & $\begin{array}{c}\text { In } \\
\text { (equiv) }\end{array}$ & $\begin{array}{c}\mathrm{DMF} \\
\text { (equiv) }\end{array}$ & Solvent & $\begin{array}{c}\text { Isolated vield } \\
(\%)\end{array}$ \\
\hline 1 & 1.1 & 2.0 & hexane & 79 \\
\hline 2 & 0.6 & 2.0 & hexane & 79 \\
\hline 3 & 0.6 & 3.0 & hesante & 78 \\
\hline 4 & 0.6 & 1.0 & hesante & 75 \\
\hline 5 & 0.3 & 2.0 & hevane & 45 \\
\hline 6 & 0 & 2.0 & hexante & 0 \\
\hline 7 & 0.6 & 0 & hevane & 0 \\
\hline 8 & 0.6 & 2.0 & cyclohexane & 78 \\
\hline 9 & 0.6 & 2.0 & pentane & 76 \\
\hline 10 & 0.6 & 2.0 & benzente & 68 \\
\hline 11 & 0.6 & 2.0 & $\mathrm{CH}_{2} \mathrm{Cl}_{2}$ & 78 \\
\hline 12 & 0.6 & 2.0 & $\mathrm{ClCH}_{2} \mathrm{CH}_{2} \mathrm{Cl}$ & 77 \\
\hline 13 & 0.6 & 2.0 & THF & 70 \\
\hline 14 & 0.6 & 20 & dionane & 71 \\
\hline 15 & 0.6 & 2.0 & diethyl ether & 69 \\
\hline 16 & 0.6 & 2.0 & $\mathrm{CH}_{3} \mathrm{CN}$ & 89 \\
\hline
\end{tabular}

dium metal. These inherited merits of indium prompted us to investigate indium-mediated reactions. ${ }^{12}$ We herein report on an indium metal-mediated synthesis of symmetrical carboxylic acid anthydrides from acyl chlorides in the presence of DMF. ${ }^{14}$

When a solution of benzoyl chloride. DMF and indium powder in hexane was stirred at room temperature for $3 \mathrm{~h}$. benzoic anhydride was obtained in $79 \%$ yield (Table 1 . entry 1). The amount of indium powder could be reduced to 0.6 equiv without a detrimental effect on the yields of benzoic anhydride (entries 2-4). The efficiency of the reaction drastically decreased with less than 0.3 equiv of indium powder, showing that the reaction is not catalytic (entry 5). Controlled experiments revealed that the reaction did not proceed without indium powder or DMF (entries 6 and 7). These results inply that indium and DMF play a crucial role in the reaction. The solvent effects on the reaction were also examined. The reactions carried out in hydrocarbon or cllorinated hydrocarbon solvents afforded benzoic anhydride in good yields (entries $8-12$ ). The reactions performed in ethers such as THF, dioxane and diethyl ether gave somewhat lower yields (entries 13-15). Among the solvents examined, the best choice was acetonitrile (entry 16)

We applied the optinal reaction conditions to preparation of structurally diverse antydrides. ${ }^{15}$ The results are presented in Table 2. The reaction show s the generality for a wide range of acyl chlorides. Aromatic and aliphatic acyl chlorides afforded the corresponding anhydrides in high isolated yields. Compared with electron-rich aromatic acyl chlorides, electron-deficient aromatic acyl chlorides gave the products in higher yields (entries $1-5$ ). The reaction with heteroaromatic acyl chlorides proceeded to give high yields of the corresponding carboxy lic acid anlydrides (entries 6 and 7). The reaction with aliphatic acyl chlorides required longer reaction times to be completed than the reaction with aromatic acyl chlorides (entries 8-11). Sterically hindered acyl chloride such as pivaloyl chloride was also converted smoothly into the corresponding carboxylic acid anhydride in high yield (entry 13). Interestingly, the reaction times for cyclic aliphatic acyl chlorides were shorter than those of acyclic aliphatic acyl chlorides under the reaction conditions (entries 14-15).

It is assumed that indium metal promotes the formation of Vilsmeier-type iminium salt with a carboxy late anion as counter anion. which reacts with an acyl cluloride to give the corresponding carboxy lic acid anhy dride via a ty pical nucleophilic acyl substitution reaction process. ${ }^{16}$ 
Table 2. Synthesis of symmetrical carboxylic acid anlydrides from acyl chlorides in the presence of In powder and DMF.

\begin{tabular}{|c|c|c|c|}
\hline Entry & Acid chloride & $\underset{(\mathrm{h})}{\mathrm{Time}}$ & $\begin{array}{c}\text { Isolated yield } \\
(\%)\end{array}$ \\
\hline 1 & & 3 & 77 \\
\hline 2 & & 3 & 88 \\
\hline 3 & & 3 & 79 \\
\hline 4 & & 2 & 96 \\
\hline 5 & & 2 & 97 \\
\hline 6 & & 3 & 82 \\
\hline 7 & & 3 & 79 \\
\hline 8 & $\mathrm{CH}_{3} \mathrm{CH}_{2} \mathrm{I}_{5} \mathrm{COCl}$ & 18 & 75 \\
\hline 9 & $\mathrm{CH}_{3}\left(\mathrm{CH}_{2}\right)_{6} \mathrm{COCl}$ & 18 & 79 \\
\hline 10 & $\mathrm{CH}_{3}\left(\mathrm{CH}_{2}\right)_{14} \mathrm{COCl}$ & 15 & 81 \\
\hline 11 & & 12 & 80 \\
\hline 12 & & 12 & 81 \\
\hline $1 \hat{3}$ & & 12 & 90 \\
\hline 14 & & 3 & 80 \\
\hline 15 & & 3 & 93 \\
\hline
\end{tabular}

In conclusion, we have developed a simple, mild and efficient method for synthesizing symmetrical carboxylic acid anlyydrides from acyl chlorides. The method shows the generality for a wide range of sterically diverse acyl chlorides.

Acknowledgments. This work was supported by the Center for Bioactive Molecular Hybrids.

\section{References}

1. (a) Oglianuso, M. A.; Wolfe, T. F. Sinthesis of Carboxtic Actds,
Esters and Their Dertwatives: Ioln Wiley \& Sons: New York, 1991; pp 198-217. (b) Holzapfel, C. W.: Pettit, G. R. J. Org Chem. 1985, 50, 2323. (c) Mariella, R. P.; Brown, K. H. Can. J. Chem. $1971,49,3348$.

2. (a) Hajipour, A. R.; Mazloumi. G. Synth Commm 2002,32, 23. (b) Tayor, E. C.; McLay, G. W. McKillop, A. J. Am Chem. Soc. 1968. 90. 2422. (c) Ferris. A. F.: Enmons. W. D. J. Am. Chem. Soc. $1953,75,232$.

3. (a) Nakanishi, W. Ikeda, Y.; I wamura, H. J. Ong. Chent 1982. 47,2275, (b) Kawanami, Y.: Dainobu, Y.; Inanaga, J:: Katsuki, T.: Yamaguchi, M. Bull. Chem. Soc. Jph. 1981, 54, 943.

4. (a) Kazemi, F.: Kiasat, A. R.; Mombaini, B. Sinth. Commum. 2007, 37, 3219. (b) Kazemi, F; Kiasat, R. Phosphorus Sulfur Silicon Relat. Elem. 2003, 178, 2287. (c) Fite, W. K.; Zhang, Z. D. Tetrahedron Letr. 1986, 27, 4937 .

5. (a) Kocz, R.: Roestamadii, J.: Mobashery, S. J. Org. Chem. 1994, 59, 2913. (b) Rinderknecht, H.; Ma, V. Helw Chm .Acta $1964,47,162$

6. (a) Clarke. P. A.: Kavalech. N. E.: Smith. M. A.: Baker. I. R.: Bird, S. J.: Chan. C. J. Ong Chem 2002, 67, 5226 (b) Stadler. A.: Kappe, C. O. Tetrahedron 2001, 57, 3915. (c) Hata, T: Tajima, K.; Mukaivama, T. Bull. Chem. Soc, Jm 1968, H, 2746. (d) Rammler. D. H.: Khorans, H. G. J. Am. Chem. Soc. $1963,85,1997$.

7. (a) Kawamura, Y.: Sato, Y.: Horie, T.; Tsukayama, M. Tetrahedron Lett. 1997, 38, 7893, (b) Mestres, R.; Palomo, C. Sinthesis 1981, 218.

8. Keshavamurthy, K. S.; Vartkar, D. Y; Dhar, D. N. Symthesis 1982, 506.

9. Kita, Y.; Akai, S.; Aimura, N.: Yoshigi, M.: Tsugoshi, T.; Yasuda, H.; Tamura, Y. J. Org. Chent. 1986, 51,4150.

10. Kaminski, Z. T.: Kolesinska, B.; Malgorzata, M. Sinth. Conmtht. $2004,34,3349$.

11. Kim, T-G.; Jang, D. O. Sunth Commm 2001, 31,395

12. (a) Li, C.-T. Tetwhedron 1996, 52, 5643. (b) Lubineau, A: Auge, J.; Queneau, Y. Sinthesis 1994 741. (c) Li, C.-J. Chem. Rev 1993, 93, 2023. (d) Araki, S.; Ito, H.; Butsugan, Y. J. Org. Chem. 1988, 53,1831

13. (a) Kim. J-G.: Tang. D. O. Sinlett 2007. 2501 (b) Jang. D. O.: Moon, K. S.; Cho, D. H.; Kim, T.-G. Tetrahedron Lett. 2006, 47 , 6063. (c) Munbunjong, W. Lee. E. H.: Chavasiri W.: Tang. D. O. Tetrahedron Lett. 2005, $\$ 6,8769$ (d) Cho, D. H., Tang, D. O. Tetrahedron Letf. 2004, 45, 2285. (e) Cho, D. H.: Kim. J-G.: Jang, D. O. Bull. Konew Chent. Soc. 2003, 24, 155. (t) Tang, D. O.: Cho. D. H. Sylent 2002, 631

14. For examples on zinc-mediated reactions, see: Serievs, A: Botuha, C.: Chemla, F.; Ferreira. F.: Perez-Luna, A. Tetrahedron

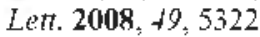

15. General procedure: To a suspension of indium powder ( $344 \mathrm{mg}$, $3.0 \mathrm{mmol})$ and DMF $(0.78 \mathrm{~mL}, 10 \mathrm{mmol})$ in $\mathrm{CH}_{3} \mathrm{CN}(5 \mathrm{~mL})$ was added acyl chloride $(5 \mathrm{mmol})$ dropuise for $5 \mathrm{~min}$ at $0{ }^{\circ} \mathrm{C}$ under argon. The reaction was allowed to be stirred for $2-18 \mathrm{~h}$ at room temperature. The reaction was monitored with TLC. After completion of the reaction, the solvent was evaporated. The residue was purified with column chromatography on silica gel affording the corresponding carbosylic acid anllydride

16. (a) Barrett, A. G. M.; Braddock, D. C.; Tames, R. A.; Koike, N.; Procopiu, P. A. J. Ong. Chem. 1998, 63, 6273. (b) Betschart C: Seebach, D. Helv. Chim .4cta 1987, 76, 2215. (c) Bosshard. H. H.: Mory, R.; Schmid, M.; Zollinger, H. Heh. Chim Acta 1959, 42,1653 . 